\title{
Study on quality management based on Internet of things technology in dam construction
}

\author{
Wenwen $\mathrm{Hu}^{\mathrm{a}}$, Bin $\mathrm{Ma}^{\mathrm{b}}$ and Jixing $\mathrm{Niu}^{\mathrm{c}}$ \\ Xijing University, Xi'an, China \\ A328337025@qq.com, b296965720@qq.com, 792842471@qq.com
}

Keywords: dam construction, quality management, Internet of things technology and knowledge management concept.

Abstract. The dam project has the characteristics of large volume of construction, complex construction environment, long cycle and difficult repair quality at the later stage of dam. If a dam break will cause casualties and property losses, it is necessary to improve the management quality of dam construction quality. Based on the analysis of the existing problems in the project, based on the Internet of things technology and knowledge management concept, the dam construction quality control and management innovation system is studied, which provides a new solution for the dam quality management, and is of great significance for the whole life cycle safety of the dam.

\section{Introduction}

The development of science and technology has led to the transformation of informatization and intellectualization of water conservancy projects. The construction of dams is the core project of water conservancy projects, and put forward higher requirements for the efficient and intelligent control of dam quality. Sun Shaonan ${ }^{[1]}$ proposed to build water conservancy information model using BIM technology to realize digital information engineering, the accurate calculation of engineering quantity, but ignored the project site quality information management, and Li Qilin ${ }^{[2]}$ and Wu Jiangang ${ }^{[3]}$ proposed the use of networking technology to solve the existing problem of water conservancy informatization, extended information network coverage, to collect project information storage complex, but not be able to make intelligent decision of engineering information, caused the related research. Liu Hui ${ }^{[4]}$ et al. Mentioned that under the influence of general IT, the development trend of water conservancy industry is knowledge automation, data processing intellectualization, and the transformation of information engineering to intelligent engineering is necessary.

These studies are combined with scientific methods and provides the development direction of management of water conservancy project, but there is no clear measures for the implementation of quality management, according to the characteristics of the dam engineering technology, using the method of networking combination of scientific knowledge is the core of building dam dam innovation management system.

\section{analysis of dam construction quality management}

the construction of dam body, there are some problems in the traditional management mode because of the large volume and long period of the construction. Material, mechanical and manual management is cumbersome, information transmission of Engineering participants is not smooth, on-site construction supervision is not scientific, and can not meet the requirements of dam quality management.

\section{the information of construction quality is inaccurate and the level of monitoring and management is limited}

The construction quality of the dam directly determines the service life of the dam, but the key processes in the implementation of the project can only be judged according to their own knowledge reserve according to the completion of the construction, which is one-sided and subjective. For the 
construction quality of concealed works, the quality of construction can only be strictly controlled from construction technology and materials. After the completion of construction, surface phenomena can only be observed, and internal quality state can not be tracked back to the service life of the dam. With the increase of service life of the dam, the quality problem of the dam appears. It is very difficult to cause the problems caused by the investigation.

\section{difficulties in management of resources in construction}

The dam construction required many kinds of raw materials and a large amount of the current use of artificial statistics, management of materials warehouse computer calculation, existing management workload, material information transparency; the construction of complex terrain, large-scale deployment of management of construction machinery and vehicles site difficult, need to manage personnel on-site command and dispatch professional, initiative poor; in charge of the construction site management directly by the construction side, the other in the work of technical personnel for lack of supervision level and work efficiency.

\section{analysis of the construction quality information obtained time consuming and laborious}

On the one hand, the construction of high quality, construction technology is complex, the construction quality in the construction of a large amount of information, collected a large amount of information, at the same time finishing is difficult, due to the construction site management experience and the uneven level of construction quality for errors of judgment.

On the other hand, the quality of information in dam construction units between the transmission channel is not smooth, The dam construction quality and management is mainly responsible for the construction, the supervisor is responsible for the supervision and management of construction unit, construction quality of dam usually take a random check form, easy to cause the quality of regulatory loopholes, the construction side can muddle through

\section{the construction quality control measures of}

In the whole life cycle of dam engineering, faced with the problem of dam construction quality, we use the technology of Internet of things and knowledge management theory to solve the problems in the construction process.

\section{Internet of things technology to obtain construction quality information}

The construction quality information is obtained from three aspects by the technology of Internet of things. First, collect the component information, using the technology of RFID networking technology, the use of component materials in the database query, you can query to the relevant material quality information, is conducive to the management of comprehensive evaluation of dam quality; tracking the raw material, can be easy to determine the safety component. Second, get construction quality inspection information, 3D laser scanner can penetrate the object presentation, collect building data, input software, reconstruct data model and calculate whether the building is safe. Third, retain the construction image data, use the webcam to collect video images of the key projects, automatically form the construction log, and do not need to sort out and find easily.

\section{to establish a database of engineering resources}

RFID technology is mainly used to build a database of engineering resources. RFID technology is a radio frequency automatic acquisition information technology, which is usually composed of RFID reader and label. The label used for management material needs information including variety, specification, quantity and result of inspection. Computer can directly record materials in and out of 
warehouse and use, and generate electronic record form according to category and date, so as to realize intelligent material management. The RFID label used for managing machinery contains mechanical type, access time and user information. Taking statistics of truck transportation times as an example, it can automatically collect truck's transport line and transport times, calculate truck workload, and generate daily mechanical workload table. The manual management is special, responsible for dam construction quality and safety, workers should wear with a RFID tag, tag input types, workers work content, play position, personal skills and other information, to realize the intelligent management on the safety of workers and workers management skills.

\section{construction quality information comparison of dam body quality knowledge management}

Dam quality knowledge management is a kind of integrated knowledge organization. It re organize the project quality inspection standards, standards and related actual cases, as well as project related professional experience organization, so as to achieve knowledge sharing and innovation. The requirements of knowledge management to comprehensive coverage of projects in different stages of the construction, and the quality control standard of refinement to each construction process, related case collection construction problems may arise, develop coping strategies used in practical engineering, project participants can improve management ability, improve project efficiency and technical level. The flow chart of the field quality management is shown in Figure 1.

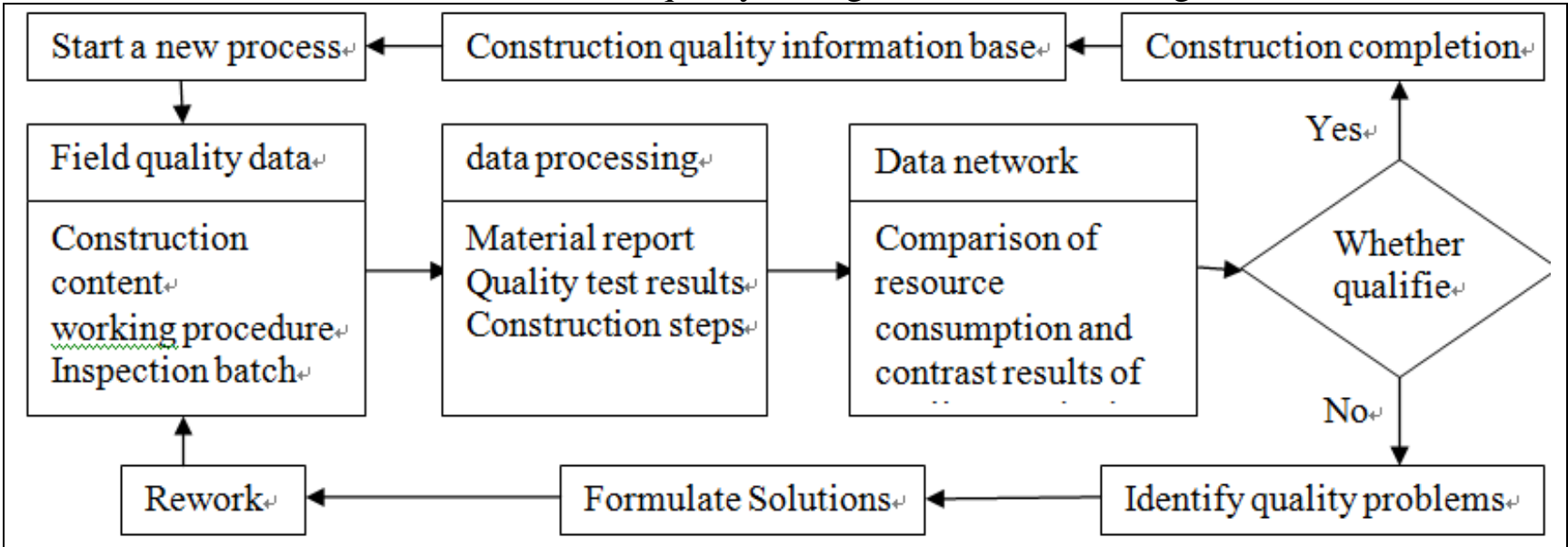

Figure 1 flow chart of field quality management

\section{information innovation system of construction quality control and control}

The quality problem of dam construction in the main field is difficult to control the quality and quality of information communication is not smooth, the construction of dam construction quality control information innovation system using Internet technology combined with the project quality knowledge management system, applied to the physical network technology in radio frequency identification, 3D laser scanner, infrared sensors and other sensing devices to collect the data of construction site norms and standards of information, knowledge management system of construction quality comparison, problem solving from construction, construction units, supervision units - online, to replace the traditional paper records, conference discussion, sampling research management mode, innovation management mode significantly improve the quality management level.

The construction quality control information system innovation covers from information collection to the network database comparison, finally realizes the intelligent solution of dam construction quality management, the whole system includes four modules: basic information collection, data processing, data network and application of decision making, system structure is shown in figure 2. 


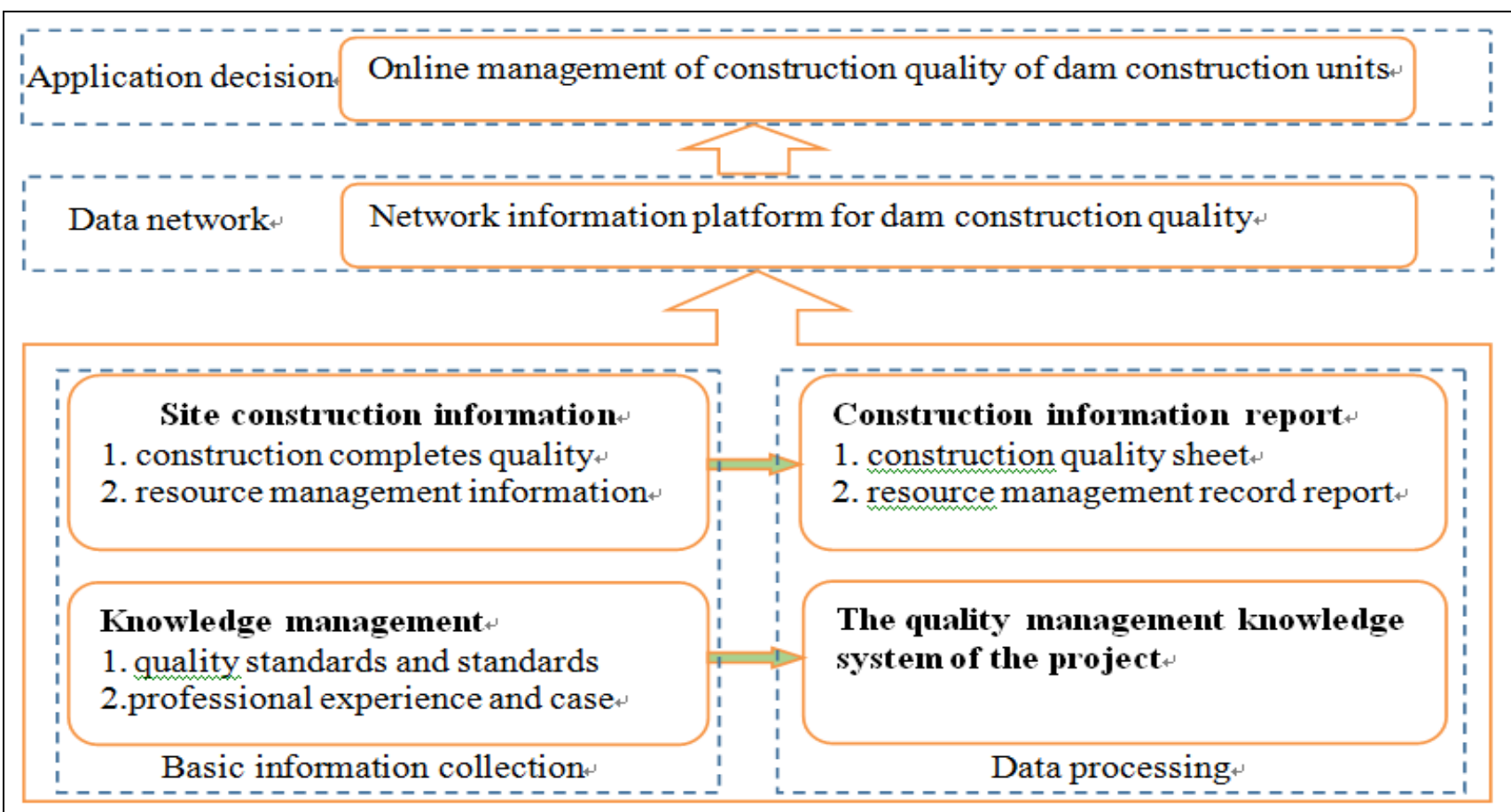

Figure 2 construction of information innovation system for construction quality control and control

\section{Conclusions}

In the construction stage of the dam, the traditional management model has not been able to keep up with the speed and strength of the modern dam construction.

Make full use of Internet technology in the construction of the value of breaking the traditional construction management mode combined with knowledge management, establish efficient dam construction quality control information system innovation, improve the quality management and control level gives a feasible development path, has certain reference significance for enterprises. Although it can effectively solve some specific problems in dam construction, the information collected by Internet of things technology is mainly presented in data form, which is not intuitive and needs further processing. How to make water conservancy projects more intelligent is worthy of continuous research.

\section{References}

[1] Shaonan Sun, Huijun Zhang, BIM technology in water conservancy engineering application study of [J]. Engineering Journal, 201630 (02): 103-108.

[2] Qilin Li. Application of Internet of things technology in water conservancy business [J]. Hunan water conservancy and hydropower, 2016 (03): 85-87+95.

[3] Jiangang Wu, Fulong Fang, Jianping Xu, Jianhong Jin, weir. The application of the Internet of things in the water control project [J]. water conservancy information, 2011 (04): 38-40+55.

[4] Hui Liu. The approach to the wisdom of water conservancy projects -- from general IT to knowledge automation to data intelligence [J]. water conservancy planning and design, 2017 (12): 81-84.

[5] Braj Kishor Mahato,Stephen O. Ogunlana. Conflict dynamics in a dam construction project: a case study[J]. Built Environment Project and Asset Management,2011,1(2).

[6] Sukru Ozcoban,Mehmet M. Berilgen,Havvanur Kilic,Tuncer B. Edil,I. Kutay Ozaydin. Staged Construction and Settlement of a Dam Founded on Soft Clay [J]. Journal of Geotechnical and Geoenvironmental Engineering,2007,133(8). 